Special Issue of the 8th International Advances in Applied Physics and Materials Science Congress (APMAS 2018)

\title{
Improvement of Tribological Properties of Steel Camshaft by Plasma Nitriding
}

\author{
A. DAYAnÇ,*, B. KARACA ${ }^{a}$ And L.C. KumruoĞLU ${ }^{b}$ \\ ${ }^{a}$ ESTAŞ Eksantrik San. ve Tic. A.Ş., 58060 Sivas, Turkey \\ ${ }^{b}$ Cumhuriyet University, Department of Metallurgy and Materials Eng., 58100 Sivas, Turkey
}

\begin{abstract}
In this study the effect of plasma nitriding on microstructure, hardness and tribological properties of 31CrMoV9 quality steel camshafts was investigated. In the first stage the NC codes to be used during the production of the steel camshaft $31 \mathrm{CrMoV} 9$ were determined by the ESPRIT program and the machining simulation and then the machining were carried out by turning-milling-grinding processes for this purpose. Plasma nitriding was conducted on machined and grinded camshafts for 120 and 240 minutes for each gas mixture at the gas mixing ratios of $80 \% \mathrm{H}_{2}+20 \% \mathrm{~N}_{2}, 90 \% \mathrm{H}_{2}+10 \% \mathrm{~N}_{2}, 94 \% \mathrm{H}_{2}+6 \% \mathrm{~N}_{2}$ at $500^{\circ} \mathrm{C}$. Plasma nitrided camshafts were examined by optical microscopy, SEM, XRD analyzes and mechanical tests (hardness and wear). For the steel camshaft made from $31 \mathrm{CrMoV} 9$ steel, the optimum hardness $(775 \mathrm{HV} 0.1)$ and the wear resistance $(1.80 \mathrm{mg} / 500$ cycles $)$, were obtained from the diffusion layer depth $(252 \mu \mathrm{m})$ and the white layer thickness $(12 \mu \mathrm{m})$ reached 240 min plasma nitriding of the $94 \% \mathrm{H}_{2}+6 \% \mathrm{~N}_{2}$ gas mixture.
\end{abstract}

DOI: 10.12693/APhysPolA.135.786

PACS/topics: machining, plasma nitriding, tribological properties, SEM

\section{Introduction}

Camshafts are known as indispensable and durable parts of power transmission systems. High load bearing capacities, operating speeds and long service life are the most important features of these materials. The camshaft cams and rocker arms are in direct contact. The cam may be subject to abrasion during the rocking motion of the shaft. Worn surfaces will cause the valves to open less, the valves to run audibly and to open and close prematurely. As a result, the slightest change in the timing of the opening-closing of the valves results in poor combustion, thereby reducing the power of the motor [1-3].

The surface properties of materials have an important place in terms of their behavior in the environment in which they are used. Machine parts operate under severe working conditions, in particular, wear, corrosion, fatigue and high temperature. They can not fulfill the demands completely and are gradually deteriorated by mechanical and/or chemical effects [4].

Many problems encountered in industrial operations are caused by wear, so various methods such as surface hardening and coating are used to increase the wear resistance, which is one of the surface properties mentioned above $[5,6]$.

The demands for engineering materials utilized in the manufacturing of machine parts, focus particularly on improvement of their functional properties and service life. On the one hand, the requirement of high strength, fatigue resistance, toughness, and on the other hand,

*corresponding author; e-mail: ayhan.dayanc@estas.com.tr resistance to corrosion and wear are only seldom fullled with standard engineering materials [7].

Suitable solution of these discult situation provides some surface treatments. Plasma nitriding is one of these manufacyuring methods. This treatment is an industrial technique that contains atomic nitrogen difusion into a ferritic steel surface. It leads to the occurrence of the compound layer on top of a zone where nitrides of the alloy elements occur in the diusion zone for increment of wear, fatigue and corrosion resistance without changing toughness and strength of the steel material [8].

Thermochemical surface treatments such as plasma nitriding are widely used in order to effectively use the steels used in machinery manufacturing and to increase the service life. It is relatively low in application cost. The surface layer formed after the nitriding process and the diffusion layer formed beneath this layer improve the wear resistance of the material [9].

In spite of many investigations on tribological behavior of nitrided steels, there are not enough studies on the tribological behavior of plasma nitrided $31 \mathrm{CrMoV} 9$ steel in terms of nitrogen amounts. Therefore, the basic goal of the work is to investigate the structural, mechanical and tribological behavior of plasma nitrided 31CrMoV9 steel under diferent nitrogen amounts.

\section{Materials and equipments}

For the elimination of possible faults before manufacturing and the determination of the cutting tools to be used, the simulation was carried out in the machine with the Esprit manufacturing simulation program (Fig. 1). The process flow diagram is organized in the form of turning, milling and grinding, respectively (Fig. 2). The steel cam was first turned into a lathe by cutting the front/back sides of the mill and the milling process was 
completed with the threading process. Finally, the production of the cam was completed by grinding of the outer corner and the grinding of the bearings. The chemical composition of the cam shaft produced from $31 \mathrm{CrMoV} 9$ steel is shown in Table I.

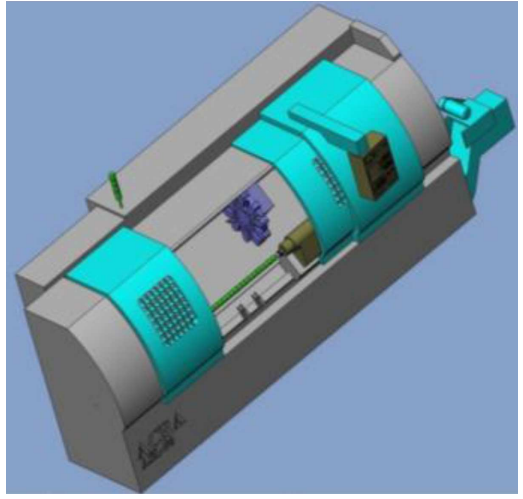

Fig. 1. Esprit model processing data.

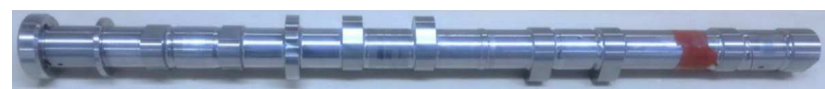

Fig. 2. Steel camshaft.

$31 \mathrm{CrMoV} 9$ steel camshaft chemical TABLE I composition \%.

\begin{tabular}{c|c|c|c|c}
\hline \hline $\mathrm{C}$ & $\mathrm{Si}$ & $\mathrm{Mn}$ & $\mathrm{Al}$ & $\mathrm{P}$ \\
\hline 0.35 & 0.37 & 0.53 & 0.11 & 0.015 \\
\hline \hline $\mathrm{Cr}$ & $\mathrm{Mo}$ & $\mathrm{Ni}$ & $\mathrm{Cu}$ & $\mathrm{V}$ \\
\hline 1.72 & 0.19 & 0.019 & 0.06 & 0.15
\end{tabular}

The measuring system consists of a vacuum pump, a gas distribution system, an energy source and a vacuum chamber made of stainless steel. The anode and cathode are placed in the vacuum chamber and the sample holder is used as the cathode. The thermocouple is connected to measure the temperature of the cathode. The samples are surrounded by a cylindrical anode. The cylindrical shape of the anode is to provide homogenous distribution of the resulting plasma to the sample.

$43 \mathrm{~mm}$ diameter, $47 \mathrm{~mm}$ high specimens were cut from the steel camshaft, grinded with 80-1200 sandpaper and polished with alumina powders of $5-3 \mu \mathrm{m}$ grains. The samples were cleaned with ethyl alcohol and were placed in a holder. The chamber was evacuated of air to a pressure of $3 \mathrm{~Pa}$ by means of a vacuum pump.

Carbon steel was used as the anode. Surface cleaning with $\mathrm{H}_{2}$ gas was carried out for 20 minutes with a lowcurrent, high-voltage DC $400 \mathrm{~V}$ source to remove contaminants from the specimens prepared before the ion nitriding process. After $\mathrm{H}_{2}$ gas was evacuated, the chamber was vacuumed again. The samples processed according to the parameters given in Table II in the plasma nitriding device shown in Fig. 3 are shown in Fig. 4.
Plasma nitriding test parameters $\left(31 \mathrm{CrMoV} 9\right.$ steel at $\left.500^{\circ} \mathrm{C}\right)$.

\begin{tabular}{c|c}
\hline \hline Nitriding duration & Gas mixture \\
\hline $2 \mathrm{~h}$ & $80 \% \mathrm{H}_{2}+20 \% \mathrm{~N}_{2}$ \\
$4 \mathrm{~h}$ & $80 \% \mathrm{H}_{2}+20 \% \mathrm{~N}_{2}$ \\
$2 \mathrm{~h}$ & $90 \% \mathrm{H}_{2}+10 \% \mathrm{~N}_{2}$ \\
$4 \mathrm{~h}$ & $90 \% \mathrm{H}_{2}+10 \% \mathrm{~N}_{2}$ \\
$4 \mathrm{~h}$ & $94 \% \mathrm{H}_{2}+6 \% \mathrm{~N}_{2}$
\end{tabular}
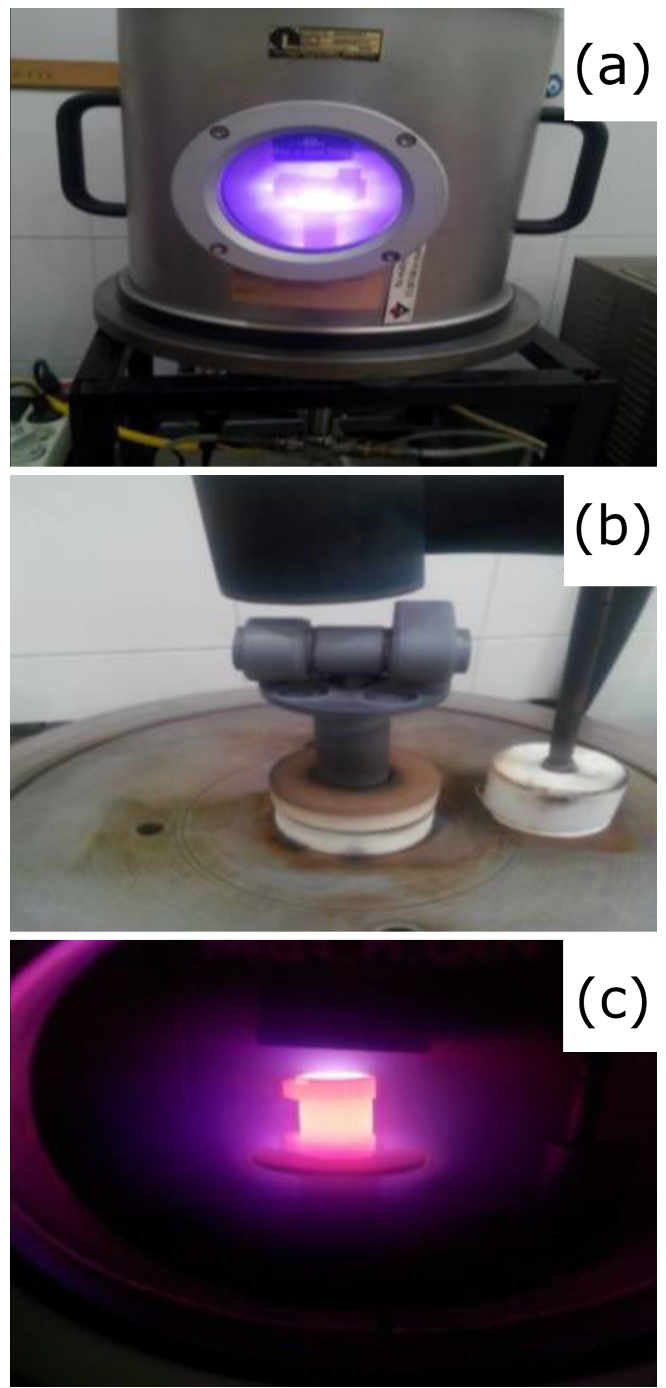

Fig. 3. Plasma nitriding application; (a) general view, (b) interior space, (c) vacuum environment.

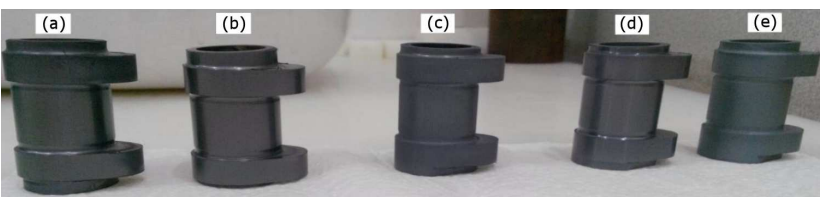

Fig. 4. Samples of steel camshaft nitrided under different conditions; (a) $80 \% \mathrm{H}_{2}+20 \% \mathrm{~N}_{2}$ for 2 hours, (b) $80 \% \mathrm{H}_{2}+20 \% \mathrm{~N}_{2}$ for 4 hours, (c) $90 \% \mathrm{H}_{2}+10 \% \mathrm{~N}_{2}$ for 2 hours, (d) $90 \% \mathrm{H}_{2}+10 \% \mathrm{~N}_{2}$ for 4 hours, (e) $94 \% \mathrm{H}_{2}+6 \% \mathrm{~N}_{2}$ for 4 hours. 
Samples were taken from the non-treated and plasmanitrided steel camshafts and the phases formed on the part surface were determined using $\mathrm{Co}-\mathrm{K} \alpha$ radiation with a wavelength of $\lambda=1.790300 \mathrm{~A}$. Match! software was used to detect phases formed on the surface. The topographic views of the samples, microstructures and wear scars were observed using SEM (Scanning Electron Microscope).

Hardness and diffusion layer thickness measurements were performed with a Qness Q10A microhardness tester under load of $10 \mathrm{~g}$ and load duration of $15 \mathrm{~s}$ in order to determine the surface hardness of the camshaft with no treated and plasma-nitrided specimens.

Hardness measurements were taken at specific distances towards the center of the sample to start from the outermost area. The hardness value measured near the surface was considered as surface hardness, and the distance to the core material hardness was determined as the depth of diffusion.

The cams were cut with a precision cutting device and flat surfaces were taken and their tribological properties were determined by carrying out wear tests. The wear volumes and surface roughness values of the samples were determined by Bruker brand 3D profilometer when the friction coefficient data were automatically taken from the machine. At room temperature, under load of $30 \mathrm{~N}$, rotation speed of $300 \mathrm{rpm}$, at 100 and $500 \mathrm{~m}$ distance, wear test with $100 \mathrm{Cr} 6$ material $5 \mathrm{~mm}$ in diameter was performed.

\section{Results and discussion}

X-ray diffraction analysis was carried out for the determination of the phases formed in the non-processed and plasma-nitrided steel cam shaft. XRD patterns taken at $2 \Theta=10-100 \mathrm{deg}$ are given in Fig. 5. In the XRD plots, it was observed that the non-nitrided structure was composed of alpha-ferrite $(\alpha-\mathrm{Fe})$ phase and only alphaferrite peaks were observed.

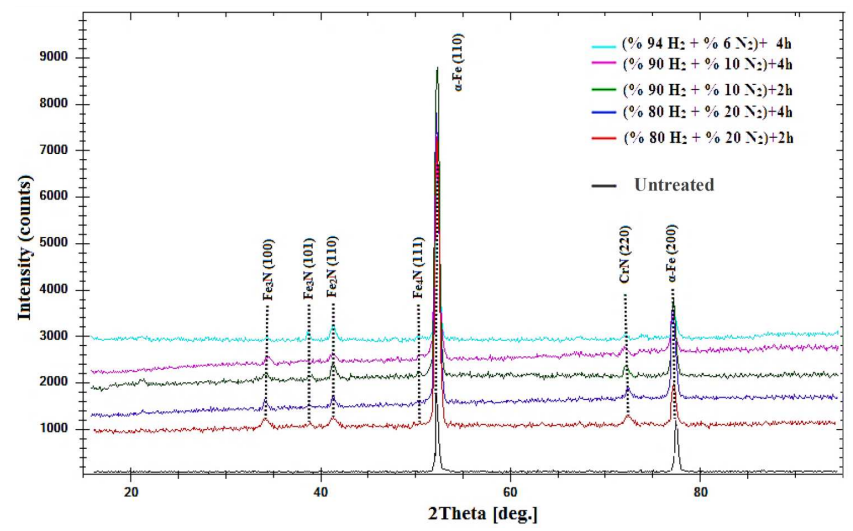

Fig. 5. XRD results of $31 \mathrm{CrMoV} 9$ steel camshaft specimens that were not machined and were nitrided under different conditions.

From the XRD peaks given in Fig. 5, it was observed that $\mathrm{CrN}, \mathrm{Fe} 2 \mathrm{~N}, \mathrm{Fe} 3 \mathrm{~N}$ and $\mathrm{Fe} 4 \mathrm{~N}$ phases were formed in the nitrided samples as a result of plasma nitridation processes at 2 hours in the $80 \% \mathrm{H}_{2}+20 \% \mathrm{~N}_{2}$ gas mixture at $500{ }^{\circ} \mathrm{C}$. The increased nitriding time seems to cause the increase in the intensity of the peaks formed by the nitrides. This is due to the increase in the nitrogen concentration in the layer with the increase of the treatment time, and the further distortion of the ferrite lattice. It was observed in the intensity of $\mathrm{Fe} 3 \mathrm{~N}$ peaks due to the increase in the hydrogen ratio in the nitrogen-hydrogen gas mixture.
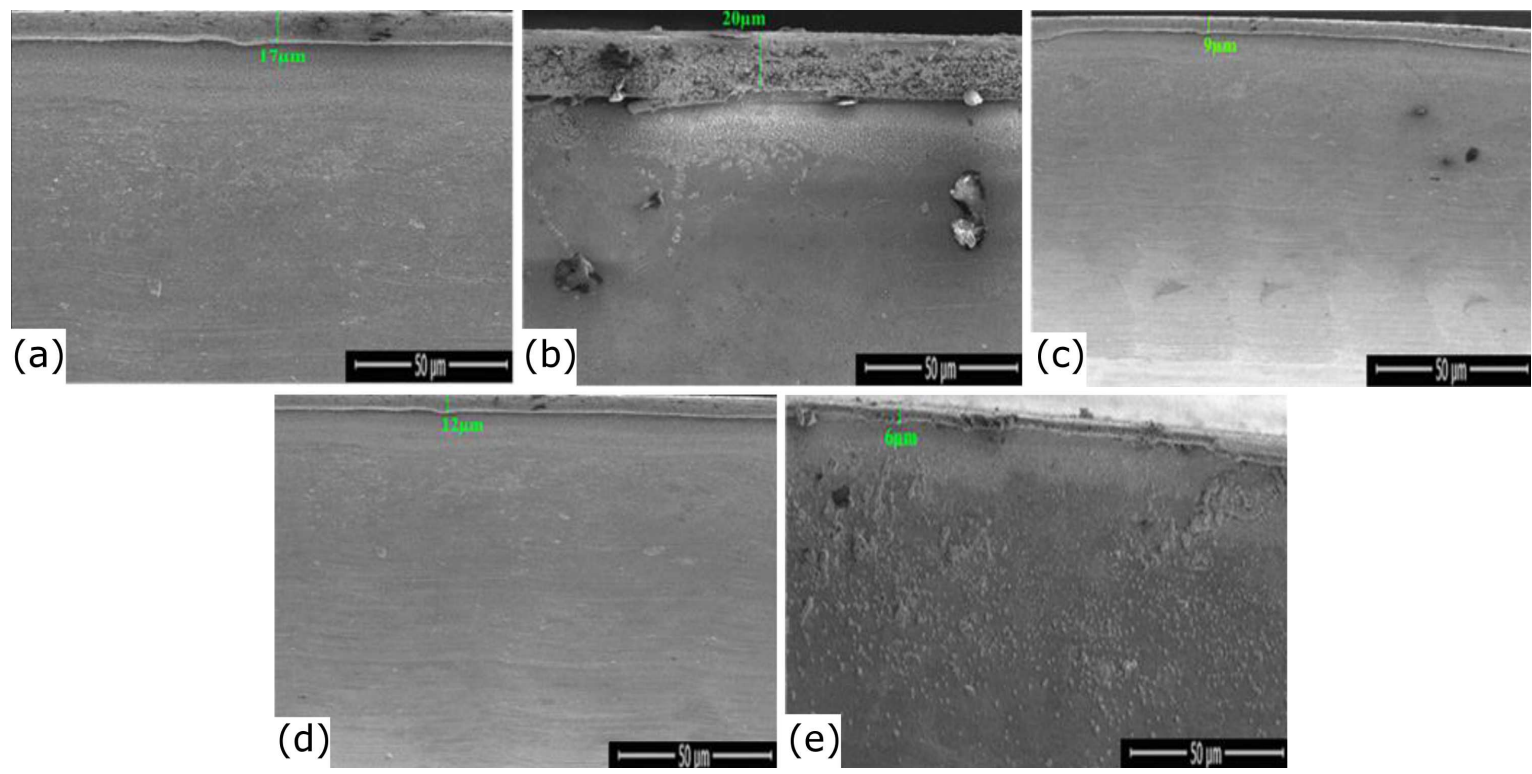

Fig. 6. SEM images of nitrided $31 \mathrm{CrMoV} 9$ steel camshaft specimens; (a) $80 \% \mathrm{H}_{2}+20 \% \mathrm{~N}_{2}$ for 2 hours, (b) $80 \% \mathrm{H}_{2}+20 \% \mathrm{~N}_{2}$ for 4 hours, (c) $90 \% \mathrm{H}_{2}+10 \% \mathrm{~N}_{2}$ for 2 hours, (d) $90 \% \mathrm{H}_{2}+10 \% \mathrm{~N}_{2}$ for 4 hours, (e) $94 \% \mathrm{H}_{2}+6 \% \mathrm{~N}_{2}$ for 4 hours. 
Cross-sectional SEM images of the nitrated samples at different process parameters are given in Fig. 6. The thickness of the white layer ranges from 6 to 20 microns (Fig. 6a; $17 \mu \mathrm{m}$, Fig. 6b; $20 \mu \mathrm{m}$, Fig. 6c; $9 \mu \mathrm{m}$, Fig. 6d; $12 \mu \mathrm{m}$, Fig. $6 \mathrm{e} ; 6 \mu \mathrm{m})$ depending on the nitriding time and gas mixture ratio. The thinnest white layer thickness $(6 \mu \mathrm{m})$ was observed in the $94 \% \mathrm{H}_{2}+6 \% \mathrm{~N}_{2}$ gas mixture for 4 hours of operation (Fig. 6e), while the thickest white layer thickness $(20 \mu \mathrm{m})$ was observed in the $80 \% \mathrm{H}_{2}+20 \% \mathrm{~N}_{2}$ gas mixture for 4 hours (Fig. 6b). The increase in the nitrogen concentration and the process time in the gas mixture led to an increase in the phase density in the white layer and a growth in the layer thickness.

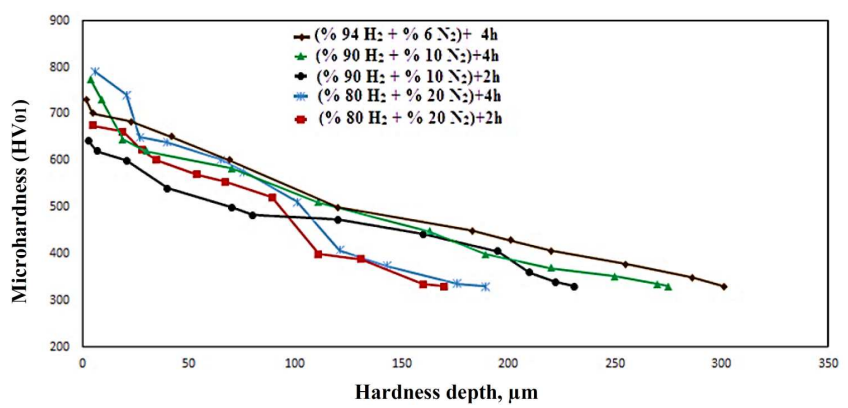

Fig. 7. Hardness distributions of $31 \mathrm{CrMoV} 9$ steel camshaft specimens non-nitrided and under different conditions.

Figure 7 shows the hardness distributions of the steel camshaft specimens. The lowest hardness value (644 HV0.1) was measured in samples nitrated for 2 hours at $90 \% \mathrm{H}_{2}+10 \% \mathrm{~N}_{2}$ gas mixture while the highest hardness value (775 HV0.1) was observed in samples nitrated for 4 hours at $94 \% \mathrm{H}_{2}+6 \% \mathrm{~N}_{2}$ gas mixture. Increased nitriding durations and the amount of hydrogen in the gas mixture led to an increase in diffusion depths and a change in the resulting microhardness curves. The increase in hydrogen in the gas mixture increases the thickness of the diffusion layer and causes higher voltage to be applied. The increase in the amount of applied voltage causes the amount of ionized gas to increase, the kinetic energy of the ions and the ionic nitrogen rate. Nitrogen contents reduction in the gas mixture increases the hydrogen share in the mixture. Due to the increased hydrogen contents the nitrogen penetrates the material easier. The surface activation ability is increased. The diffusion layer increases its thickness. Furthermore, with the reduction of the amount of nitrogen in the gas mixture, the thickness of white layer formed on the surface decreases. It looses its barrier ability, facilitating the nitrogen diffusion further. SEM images of the measured microhardness values are given in Fig. 8 (Fig. 8a; $150 \mu \mathrm{m}$, Fig. 8b; $180 \mu \mathrm{m}$, Fig. 8c; $195 \mu \mathrm{m}$, Fig. 8d; $235 \mu \mathrm{m}$, Fig. 8e; $250 \mu \mathrm{m})$.

The friction coefficient-wear distance graphs of the non-nitrated and plasma-nitrated samples of the cam against $\mathrm{Al}_{2} \mathrm{O}_{3}$ balls are given in Fig. 9. The friction coefficients of the untreated samples at a distance of $100 \mathrm{~m}$ (Fig. 9a) at $30 \mathrm{~N}$ load was 0.86 , while the distance at $500 \mathrm{~m}$ (Fig. 9b) was 0.87. As a result of plasma nitriding, lower friction coefficients was observed at both $100 \mathrm{~m}$ distance (Fig. 9a) and $500 \mathrm{~m}$ distance (Fig. 9b) according to gas mixture ratio and process time. The augmented coefficient of friction causes abrasive wear. The surface hardness of the samples increases after the nitriding process and the change of the treatment time from 2 hours to 4 hours decreases the friction coefficient with increasing surface hardness.
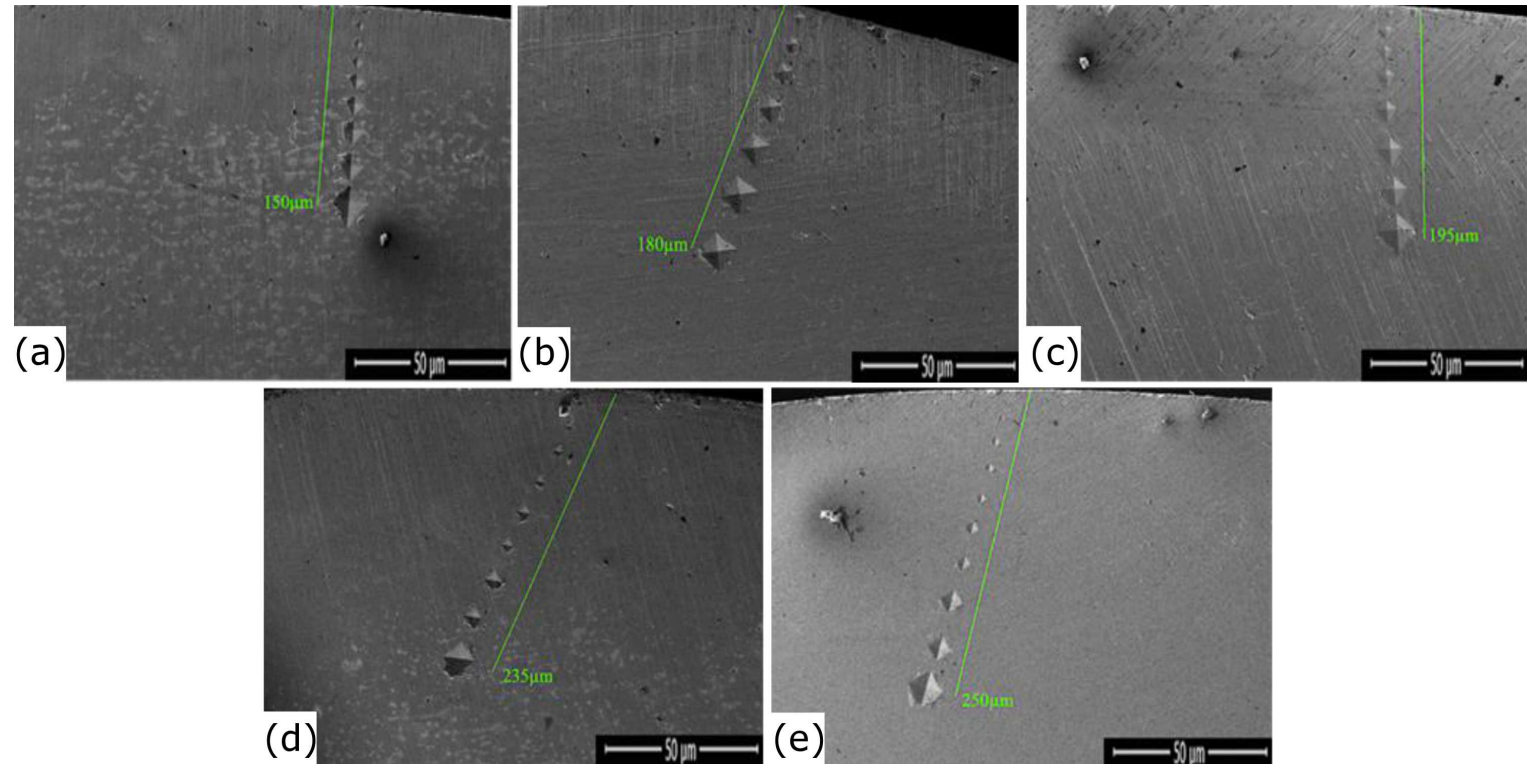

Fig. 8. Hardness depth SEM images of nitrided 31CrMoV9 steel camshaft specimens; (a) $80 \% \mathrm{H}_{2}+20 \% \mathrm{~N}_{2}$ for 2 hours, (b) $80 \% \mathrm{H}_{2}+20 \% \mathrm{~N}_{2}$ for 4 hours, (c) $90 \% \mathrm{H}_{2}+10 \% \mathrm{~N}_{2}$ for 2 hours, (d) $90 \% \mathrm{H}_{2}+10 \% \mathrm{~N}_{2}$ for 4 hours, (e) $94 \% \mathrm{H}_{2}+6 \% \mathrm{~N}_{2}$ for 4 hours. 

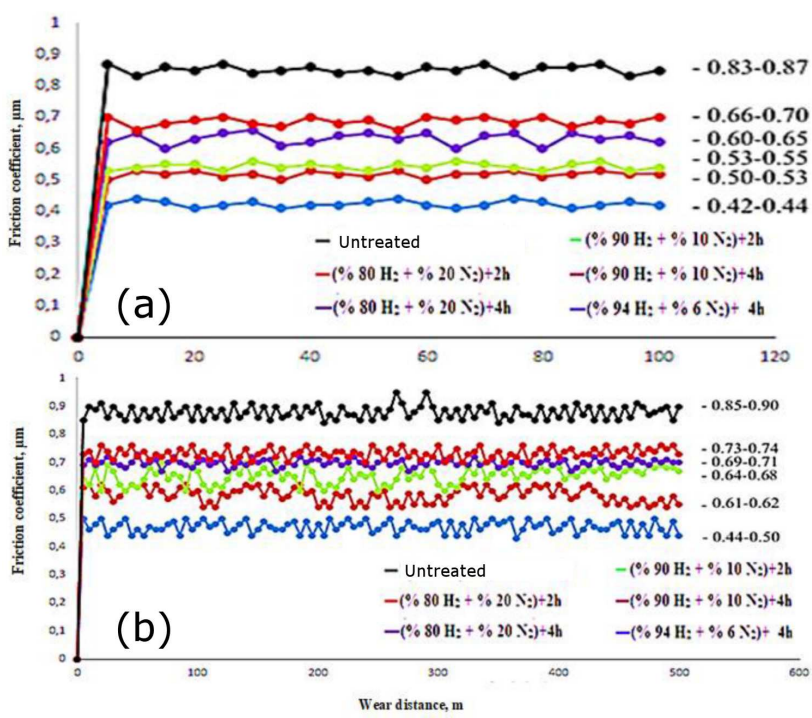

Fig. 9. Frictional coefficient-distance graph of $31 \mathrm{CrMoV} 9$ steel camshaft specimens nitrided without process and under different conditions; (a) $100 \mathrm{~m}$, (b) $500 \mathrm{~m}$.

The lowest friction coefficients were determined as 0.43 and 0.48 , respectively, for the 4 hour treatment in $94 \% \mathrm{H}_{2}+6 \% \mathrm{~N}_{2}$ gas mixture at $100 \mathrm{~m}$ (Fig. 9a) and $500 \mathrm{~m}$ (Fig. 9a) distances.

Figure 10 shows the wear rates of the camshaft specimens after $100 \mathrm{~m}$ and $500 \mathrm{~m}$ distance under $30 \mathrm{~N}$ load. After the wear test, debris volume was determined with $3 \mathrm{D}$ contactless profilmeter. After plasma nitriding, the camshafts wear resistance increases 3-4 times. Data presented in Fig. 10 suggest, that surface hardness does not seem to have a significant effect on the wear rate. More important wear factors are surface roughness and friction coefficient. Due to the low surface roughness and the coefficient of friction, the highest wear resistance was obtained in the $94 \% \mathrm{H}_{2}+6 \% \mathrm{~N}_{2}$ gas mixture, 4 hours of operation.

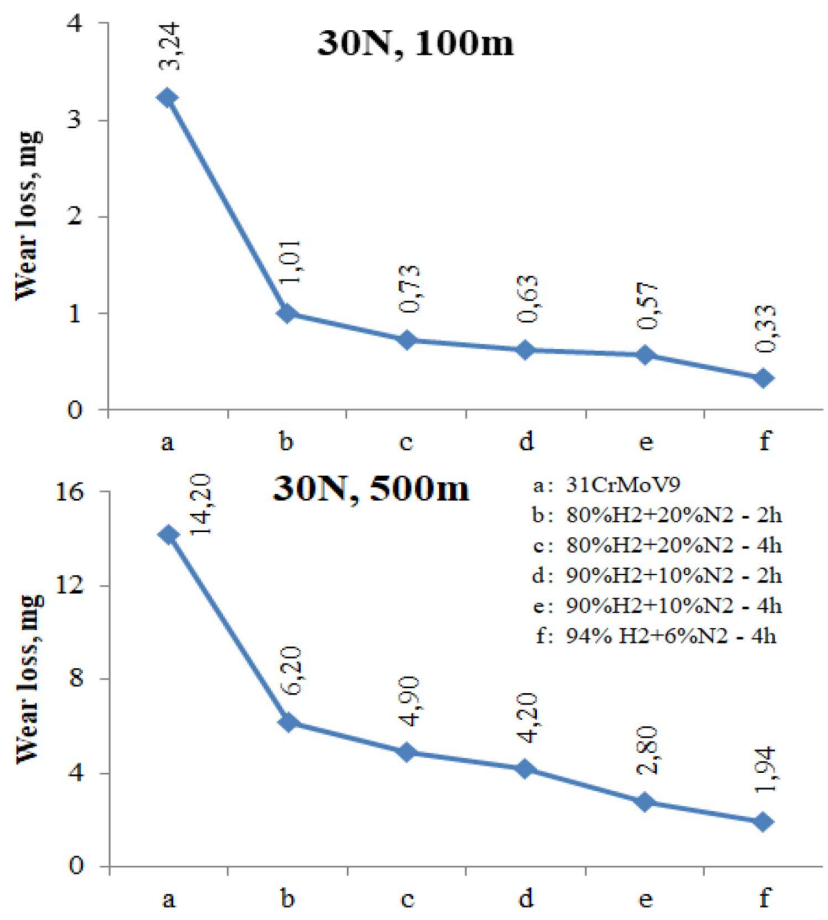

Fig. 10. Wear ratios of $31 \mathrm{CrMoV} 9$ steel camshaft specimens nitrided without process and under different conditions.
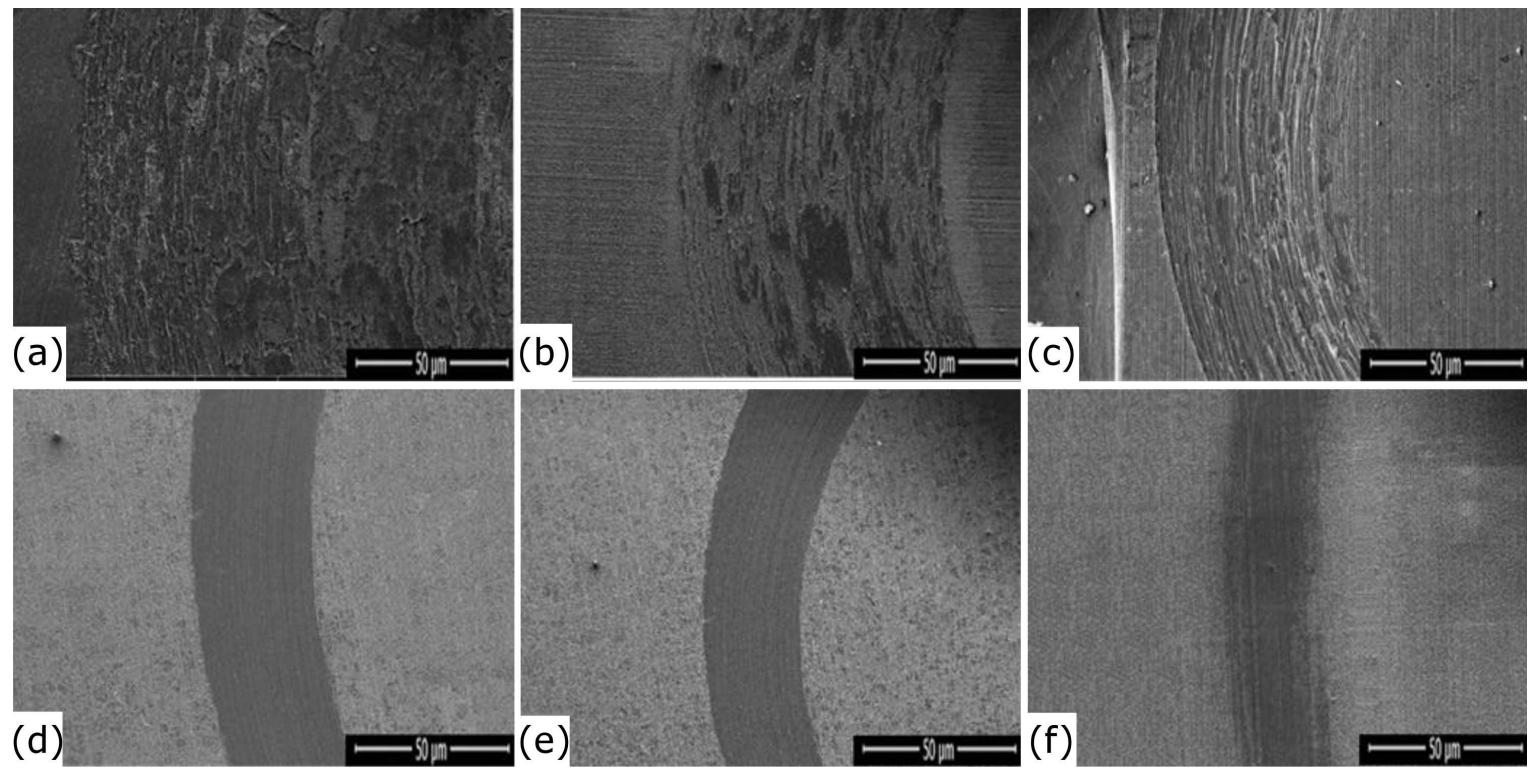

Fig. 11. Wear trace of SEM images of specimens of untreated and nitrated steel shaft without nitriding at $500 \mathrm{~m}$ distance; (a) untreated steel, (b) $80 \% \mathrm{H}_{2}+20 \% \mathrm{~N}_{2} 2$ hours, (c) $80 \% \mathrm{H}_{2}+20 \% \mathrm{~N}_{2} 4$ hours, (d) $90 \% \mathrm{H}_{2}+10 \% \mathrm{~N}_{2}$ 2 hours, (e) $90 \% \mathrm{H}_{2}+10 \% \mathrm{~N}_{2} 4$ hours, (f) $94 \% \mathrm{H}_{2}+6 \% \mathrm{~N}_{2} 4$ hours. 
Figure 11 shows SEM images of samples nitrided under different conditions after a wear test at a distance of $500 \mathrm{~m}$. When worn surface images were examined, it was seen that the non-treated and nitrided steel exhibit different wear behavior. The wear behavior of non-nitrided steel specimens (Fig. 11a) is in the form of abrasive wear. The wear behavior of nitrided specimens (Fig. 11b-e) is in the form of adhesive wear. As a result, the trace of wear is quite extensive. Nitriding leads to reduction of the possibility of adhesion between the contacting surfaces by altering the surface chemical structure and reducing the plastic deformation of the cam surfaces. The increase in hardness, surface roughness and friction coefficient due to process parameters after nitriding are the most important reasons for decreasing the wear rate of nitrided specimens. According to the results of the nitrided samples wear test, the wear trace narrows with the increase in the process time and the decrease in the nitrogen ratio in the gas mixture (Fig. 11b-e). The thinnest trace (Fig. 11e) was found in a $94 \% \mathrm{H}_{2}+6 \% \mathrm{~N}_{2}$ gas mixture, in a nitrided steel cam shaft with a 4 hour sliding period. Partly abrasive scars in the presence of adhesive layers can be seen from the traces on the surface of the sample.

Figure 12 shows wear SEM images of $31 \mathrm{CrMoV} 9$ steel camshaft specimens nitrided at 4 hours of operation in a $94 \% \mathrm{H}_{2}+6 \% \mathrm{~N}_{2}$ gas mixture tested at different wear distances. When the wear distance is increased from $100 \mathrm{~m}$ to $500 \mathrm{~m}$ (Fig. 12a-d, Table III), the width of the wear trace on the surface of both the cam and the machined cams increases. Partly abrasive scars of the presence of adhesive layers can be identified from the traces left on the surface of the sample (Fig. $12 \mathrm{a}-\mathrm{c}$ ).
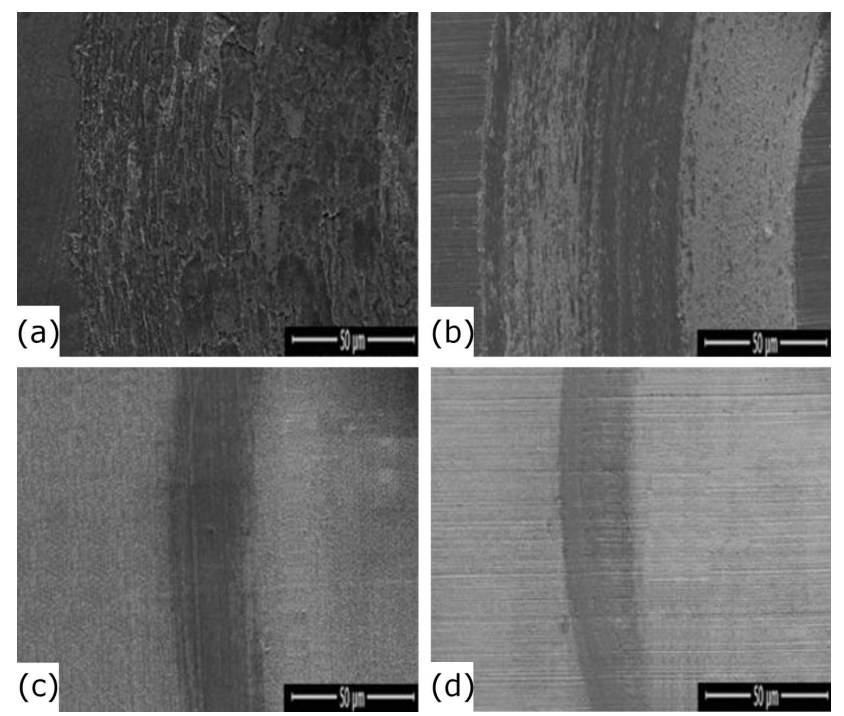

Fig. 12. Wear trace SEM images of non-treated and nitrided $31 \mathrm{CrMoV} 9$ steel camshaft specimens; (a) Non-treated $500 \mathrm{~m}, \quad$ (b) Non-treated $100 \mathrm{~m}$, (c) $94 \% \mathrm{H}_{2}+6 \% \mathrm{~N}_{2} 4$ hours, $500 \mathrm{~m}$, (d) $94 \% \mathrm{H}_{2}+6 \% \mathrm{~N}_{2} 4$ hours, $100 \mathrm{~m}$.

Test results applied to steel camshaft specimens with different plasma nitriding parameters.

TABLE III

\begin{tabular}{|c|c|c|c|c|c|c|c|c|c|c|c|}
\hline \multirow[t]{2}{*}{ Sample } & \multicolumn{3}{|c|}{ Nitriding parameters } & \multirow{2}{*}{$\begin{array}{c}\text { White } \\
\text { layer }[\mu \mathrm{m}]\end{array}$} & \multirow{2}{*}{$\begin{array}{c}\text { Diffusion } \\
\text { layer }[\mu \mathrm{m}]\end{array}$} & \multirow{2}{*}{\begin{tabular}{|c|} 
Surface \\
hardness \\
{$[$ HV0.1] }
\end{tabular}} & \multirow{2}{*}{$\begin{array}{c}\text { Surface } \\
\text { roughness } \\
{[\mu \mathrm{m}]}\end{array}$} & \multicolumn{2}{|c|}{$\begin{array}{c}\text { Friction } \\
\text { coefficient }\end{array}$} & \multicolumn{2}{|c|}{$\begin{array}{c}\text { Wear } \\
\text { loss [mg] }\end{array}$} \\
\hline & Temp. $\left[{ }^{\circ} \mathrm{C}\right]$ & Time $[\mathrm{h}]$ & Gas mixture & & & & & $100 \mathrm{~m}$ & $500 \mathrm{~m}$ & $100 \mathrm{~m}$ & $500 \mathrm{~m}$ \\
\hline 1 & 500 & 2 & $80 \% \mathrm{H}_{2}+20 \% \mathrm{~N}_{2}$ & 17 & 151 & 675 & 0.22 & 0.69 & 0.73 & 1.01 & 2.20 \\
\hline 2 & 500 & 4 & $80 \% \mathrm{H}_{2}+20 \% \mathrm{~N}_{2}$ & 21 & 180 & 791 & 0.25 & 0.63 & 0.70 & 0.73 & 4.90 \\
\hline 3 & 500 & 2 & $90 \% \mathrm{H}_{2}+10 \% \mathrm{~N}_{2}$ & 9 & 197 & 644 & 0.13 & 0.54 & 0.65 & 0.63 & 4.20 \\
\hline 4 & 500 & 4 & $90 \% \mathrm{H}_{2}+10 \% \mathrm{~N}_{2}$ & 6 & 237 & 733 & 0.15 & 0.52 & 0.60 & 0.57 & 2.80 \\
\hline 5 & 500 & 4 & $94 \% \mathrm{H}_{2}+6 \% \mathrm{~N}_{2}$ & 12 & 252 & 775 & 0.12 & 0.43 & 0.48 & 0.33 & 1.80 \\
\hline $31 \mathrm{CrMoV} 9$ & 500 & - & - & - & - & 330 & 0.07 & 0.86 & 0.87 & 3.24 & 19.00 \\
\hline
\end{tabular}

\section{Conclusions}

In order to increase the mechanical and microstructure properties of the camshaft used in vehicle engines to higher levels, plasma nitriding processes were performed under different conditions. In this study, camshafts produced from a 31CrMoV9 quality nitrated steel were used. These camshafts are aimed to increase the mechanical microstructure properties that have been nitrided at low temperatures. Wear, hardness, surface properties and microstructures of the obtained samples were investigated and the results are listed below.

1. Alpha-ferrite $(\alpha$-Fe) peaks were observed in XRD plots of samples of non-nitrided steel camshaft.

2. On the surface of the plasma nitriding finish, a modified diffusion layer consisting of $\mathrm{CrN}, \mathrm{Fe} 2 \mathrm{~N}$, Fe3N and Fe4N phases was formed depending on the process parameters. With the increase in the process time and the increase in the nitrogen content in the gas mixture, the density of these nitrogen-bound phases also increased.

3. Performing the plasma nitriding, the thinnest white layer of $12 \mu \mathrm{m}$ was obtained in $94 \% \mathrm{H}_{2}+6 \% \mathrm{~N}_{2}$ gas mixture after $4 \mathrm{~h}$ treatment period. The thickest white layer of $21 \mu \mathrm{m}$ was observed in $80 \% \mathrm{H}_{2}+20 \% \mathrm{~N}_{2}$ gas mixture after $4 \mathrm{~h}$ of operation.

4. The nitriding diffusion layer was found to be separated from the base material by a distinct line.

5. Plasma nitridation of the $31 \mathrm{CrMoV} 9$ nitridation steel camshaft specimens resulted in a thinner diffusion layer depth of $80 \% \mathrm{H}_{2}+20 \% \mathrm{~N}_{2}$ gas mixture at $151 \mu \mathrm{m}$ for 2 hours of operation. The depth 
of the thickest diffusion layer was found to be for $94 \% \mathrm{H}_{2}+6 \% \mathrm{~N}_{2}$ gas mixture and $2525 \mu \mathrm{m}$ for 4 hours of operation.

6. After nitridation the surface hardness of the camshaft increases. The highest hardness value was observed in $94 \% \mathrm{H}_{2}+6 \% \mathrm{~N}_{2}$ gas mixture as 775 HV0.1 over 4 hours of operation.

7. The $31 \mathrm{CrMoV9}$ steel camshaft sample was subjected to a wear test at a distance of $100 \mathrm{~m}$ and $500 \mathrm{~m}$ under a load of $30 \mathrm{~N}$, and the plasma nitriding process was found to increase wear resistance. The best abrasion resistance was observed in $94 \% \mathrm{H}_{2}+6 \% \mathrm{~N}_{2}$ gas mixture as $1.80 \mathrm{mg}$ at a distance of $500 \mathrm{~m}$ during the 4 hour treatment period. It has also been observed that the abrasion resistance increases with the increase in the nitriding process time.

8. With the application of the nitrification process; the surface roughness of the sample increased and the friction coefficient decreased.

\section{References}

[1] W. Gui, J. Lin, Sci. Rep. 7, 165 (2017).

[2] S.Q. Wang, M.X. Wei, Y.T. Zhao, Wear 269, 424 (2010).

[3] D.J. Shen, Y.L. Wang, P. Nash, Mat. Sci. Eng. A 458, 240 (2007)

[4] M.D. Bermúdez, P. Iglesia, A.E. Jiménez, Wear 267, 1784 (2009).

[5] C.C. Wang, J.R. Hwang, Surf. Coat. Tech. 64, 29 (1994).

[6] V.N. Duradji, D.E. Kaputkin, J. Electr. Soc. 163 , 306 (2016).

[7] S.F. Luk, T.P. Leung, W.S. Miu, J. Mat. Proc. Tech. 63, 833 (1997).

[8] J. Suchanek, V. Kuklik, Wear 267, 2100 (2009).

[9] A. Çelik, S. Karadeniz, Surf. Coat. Tech. 72, 169 (1995). 